\title{
Association between the Performance of the University Security Officers and Their Physical Fitness: A Case Study
}

\author{
A. M. Razmy' ${ }^{1}$ A. Jabeer ${ }^{2}$ \\ ${ }^{1}$ Department of Mathematical Sciences, Faculty of Applied Sciences, South Eastern University of Sri Lanka, Sammanthurai, \\ Sri Lanka \\ ${ }^{2}$ Cheif Security Office, South Eastern University of Sri Lanka, Oluvil, Sri Lanka \\ Email: amrazmy@seu.ac.lk
}

How to cite this paper: Razmy, A.M. and Jabeer, A. (2017) Association between the Performance of the University Security Officers and Their Physical Fitness: A Case Study. Open Access Library Journal, 4: e3239. https://doi.org/10.4236/oalib.1103239

Received: November 8, 2016

Accepted: June 9, 2017

Published: June 12, 2017

Copyright $\odot 2017$ by authors and Open Access Library Inc.

This work is licensed under the Creative Commons Attribution International License (CC BY 4.0).

http://creativecommons.org/licenses/by/4.0/ (c) (i) Open Access

\begin{abstract}
Physical fitness is considered to be a vital factor for performing any duty. Specially in the university security service, this factor is given more priority when employing the officers. In this case study, association between the performance of the university security officers and their physical fitness was studied. All male university security officers in the permanent and contract category working in the South Eastern University of Sri Lanka were assessed for their performance and their physical fitness were measured in terms height, weight, blood pressure, physical appearance, neck circumference and record of long lasting diseases. This study found no performance difference between permanent and contract employees but the variation in performance is much higher among the permanent employees. No relationship was established between performance and age or BMI. The physical appearance of the officer is a much influencing factor of determining the performance.
\end{abstract}

\section{Subject Areas}

Case Studies and Management Information Systems

\section{Keywords}

Physical Fitness, Security, University Security Officer

\section{Introduction}

Safety and security issues of the universities have become an important issue in the current world. Universities have to ensure the safety and security of the institute because it is an important aspect of selecting a tertiary institution for ad- 
mission by the students and parents [1]. The concept of campus security began when Henry Fielding developed the idea of crime prevention in 1748 [2]. The first campus security department was established in Yale University in 1894 [3]. Campus security in general declined until the 1920s when watchmen were employed to protect college property. Subsequently, institutions started recruiting retired police officers to run campus security. In the 1950s, it was started to recruit professional security officers into the campus with the uniforms [4]. The service of the university security system is a major component that gives a professional image to the institution [5] [6]. Physical fitness and health of the university security officer (USO) is a significant factor in achieving the excellence performance of expected duties in the universities. The very best USOs keep themselves within a healthy weight range and exercise regularly to be healthy and fit. A security guard should look well put together and portray themselves and the client in a positive manner [7] [8]. USO must be physically fit for many reasons including for job performance, reducing the risk of future diseases, stress reduction, and shift schedules. Physically fit security officers are better able to provide high levels of organizational safety and customer service for employees, consumers and visitors [9]. A USO's lifestyle should include regular exercise, proper nutrition intake, stress management, substance-abuse prevention, and health-risk management. It can be believed the physical fit USOs can perform better in the service. With these thoughts, a case study was carried out to find the exact association between USOs' performance and physical fitness in the South Eastern University of Sri Lanka (SEUSL).

\section{Methodology}

This case study was carried out in the SEUSL located in the Eastern province of Sri Lanka. The entire 84 male USOs working in the SEUSL under permanent (36\%) and contract basis (64\%) were included in this study. Height, weight, blood pressure, physical appearance, neck circumference and record of long lasting diseases were considered to measure the physical fitness of the USO. The performance of the USO is measured based on the indicators attendance, punctuality, staff relationship, contributes to positive work, exhibition of service oriented attitude, courteous, requirement of minimal supervision and responsiveness to supervision. The indicators except the attendance were measured using Likert scale where head of the USO scored for the indicators for each individual. These indicators were translated to one performance factor (PF) after a reliability test which yielded Cronbach's Alpha value of 0.7821 . These seven indicators were subjected to a factor analysis using the SPSS version 16.0. The factor analysis used the principal component analysis using the rotation method of Varimax with Kaiser Normalization. The rotation converged into one factor called PF.

\section{Results and Discussion}

The average age of USOwas38.6 years $(95 \% \mathrm{CI}, 36.3,40.9)$ but the permanent 
university USOs (PUSOs) were 10.5 years significantly older than the contract USOs (CUSOs) $(\mathrm{p}<0.000)$. This danger scenario arises because once the university recruits a PUSO, he serves till his retirement age of 55 years. Average height of USO was $165.6 \mathrm{~cm}(95 \% \mathrm{CI}, 163.7,167.5)$ whereas no significant difference was observed in heights between PUSO and CUSO ( $\mathrm{p}=0.160$ ). The average weight of the USO was $63.8 \mathrm{~kg}(95 \% \mathrm{CI}, 64.4,69.5)$ but the PUSOs were $8.6 \mathrm{~kg}$ heavier than the CUSOs $(\mathrm{p}=0.002)$.The average systolic and diastolic body pressures were $119.5 \mathrm{mmHg}$ and $82.5 \mathrm{mmHg}$ (95\% CI, 118.1, 120.9 and 80.0, 85.0) respectively. No significant difference was observed in body pressures between PUSO and CUSOs. $(\mathrm{p}=0.06)$. The average chest width of a USO was 90.4 $\mathrm{cm}(95 \% \mathrm{CI}, 89.9,92.0)$. Again no significant difference was observed in body chest width between PUSO and CUSOs. $(\mathrm{p}=0.86)$. The average BMI of USOs was 24.4 (95\% CI, 23.5, 25.4). But, the PUSOs had 2.2 BMI unit higher than the CUSOs $(\mathrm{p}=0.022)$. This is again shows the disadvantage of having PUSOs for a long time. In overall $40.5 \%$ of the USOs were in overweight category (BMI $\geq 25$ ) whereas this percentage was 56.7 for the PUSOs and 31.5 for CUSOs and therefore it shows a significant association $(\mathrm{p}=0.003)$.The average neck circumference of PUSO and CUSOs were $39.6 \mathrm{~cm}$ and $37.8 \mathrm{~cm}$ respectively. A significant $1.8 \mathrm{~cm}$ higher neck circumference was observed for PUSO $(\mathrm{p}=0.005)$ like the case in BMI. This observation partly supports the study of Liubov and Arie that the circumference of neck has a relationship with BMI [10]. But any exact relationship was not observed in this study.

The performance of the USOs were measured indirectly by the punctuality, staff relationship, contributes to positive work, exhibition of service oriented attitude, courteous, requirement of minimal supervision and responsiveness to supervision. The average number of leave taken by a USO was 10.5 days per year (95\% CI, 8.2, 12.7). The PUSOs had taken an average of 18.9 days per year whereas for CUSOs, it was 5.8 days per year. This difference was highly significant ( $\mathrm{p}$ $<0.000$ ). Even though this leave difference was not highlighted in the performance of the employees, this leave difference affect the performance of the institution. Figure 1 shows the relationship between the age of the USOs and number of days leave taken. A significant increase, from 6.2 to 18.6 days leave was observed for the more than 40 years age group USOs compare to younger age USOs $(\mathrm{p}<0.000)$. The reason for this increase might be due to their physical condition or increased social responsibilities.

The PF had no significant relationship with BMI or age, and it is shown in Figure 2 and Figure 3 respectively. Surprisingly, the significant different in BMI and age observed between the PUSO and CUSO had not created any differences in PF.

No significant difference in performance was observed between the PUSOs and CUSOs $(\mathrm{p}=0.317)$ but the variation in PF among the PUSOs is higher compare to the CUSOs. This could be observed in Figure 4. This again shows the danger of permanent employment. The physical appearance plays a major role in the performance of the USOs. Figure 5 shows that the PF of USOs in- 
creases with the physical appearance score which seems to be major factor in affecting the performance.

\section{Conclusion}

The PUSOs are 10.5 years significantly older than the contract CUSOs. This will lead to a problem of having very old USOs in the next ten years due to the sys-

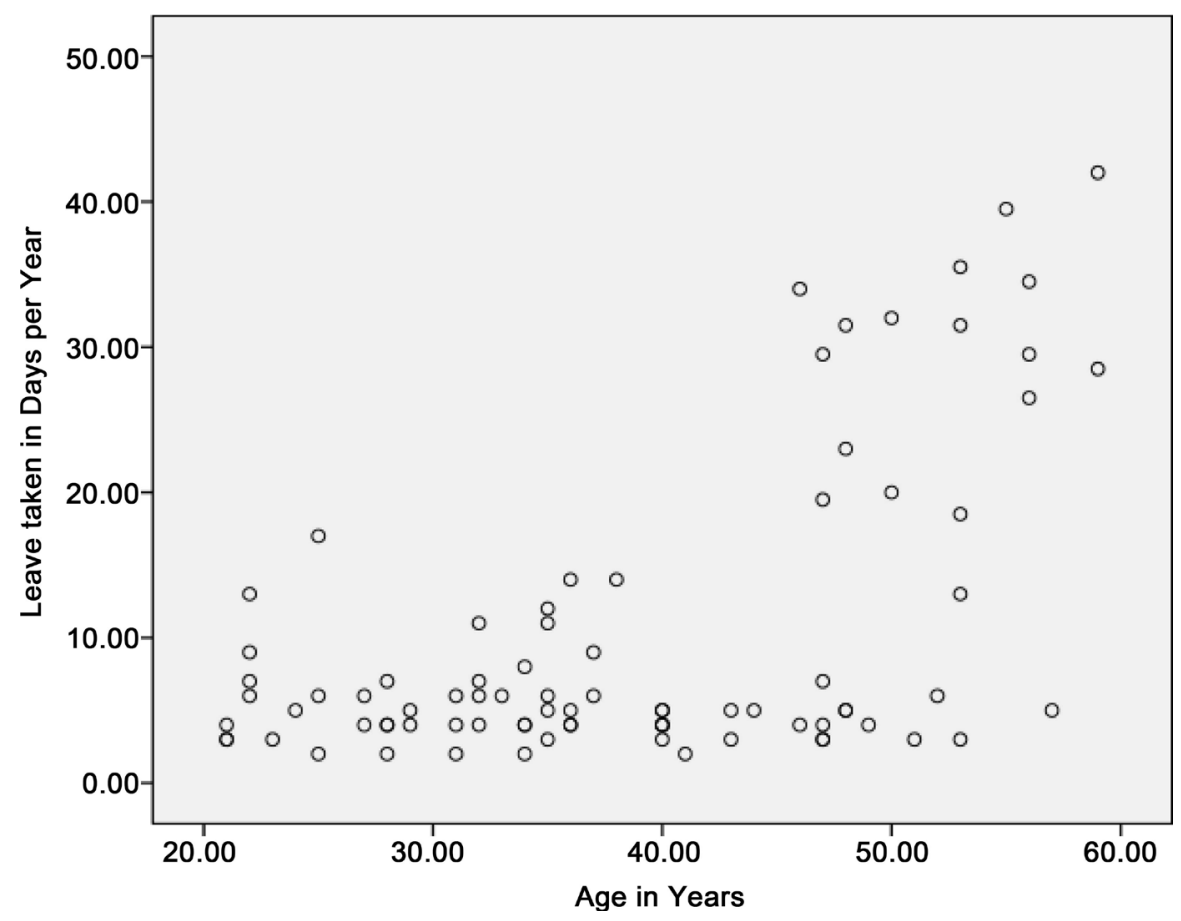

Figure 1. Relationship between Age of USOs and Leave taken.

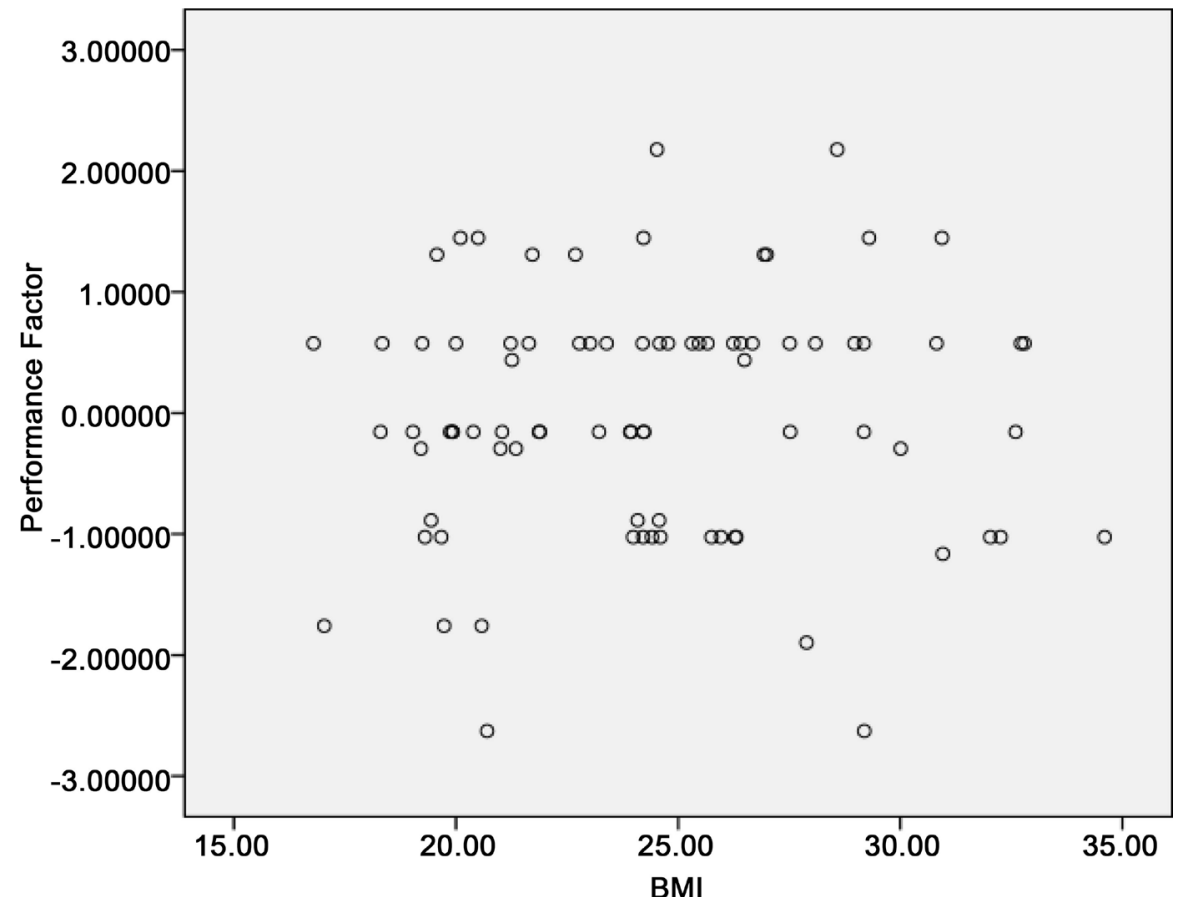

Figure 2. Relationship between BMI and PF. 


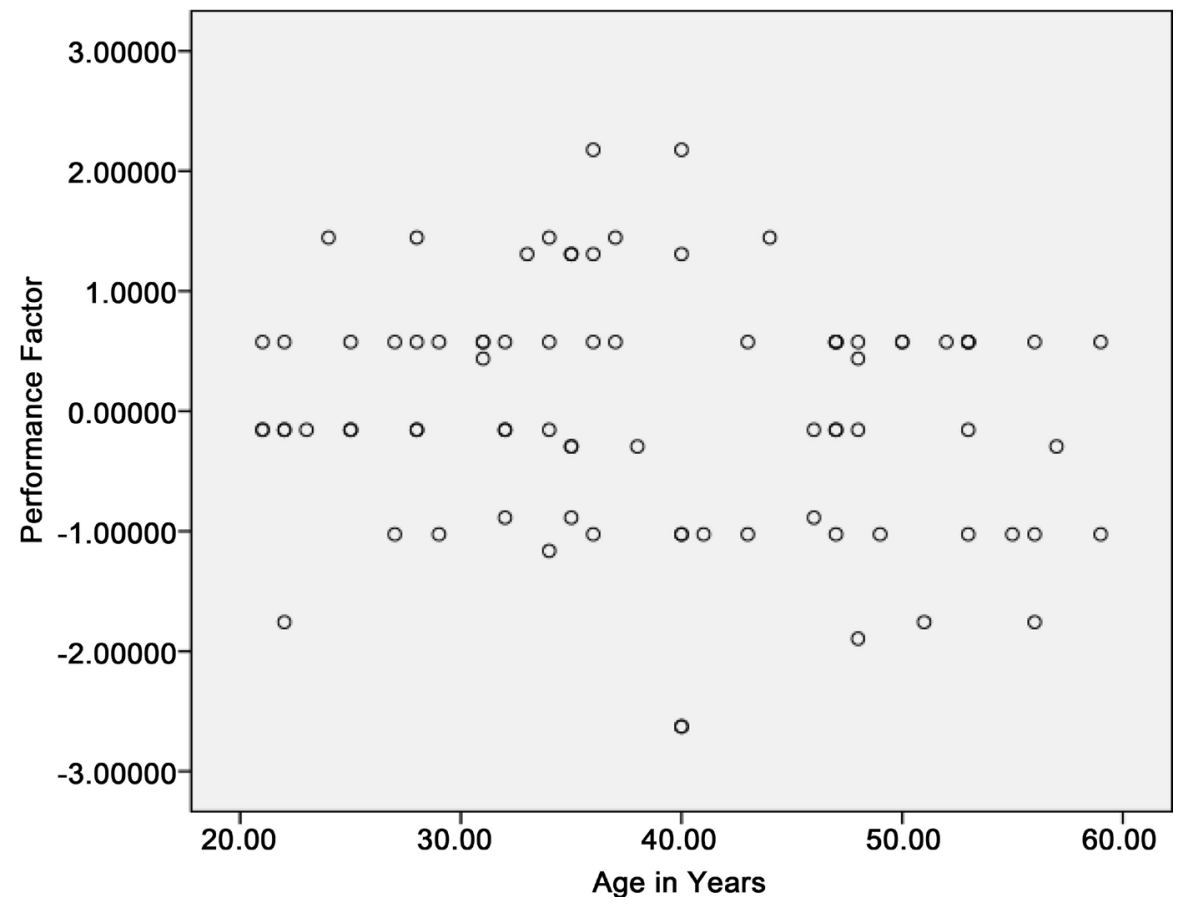

Figure 3. Relationship between Age and PF.

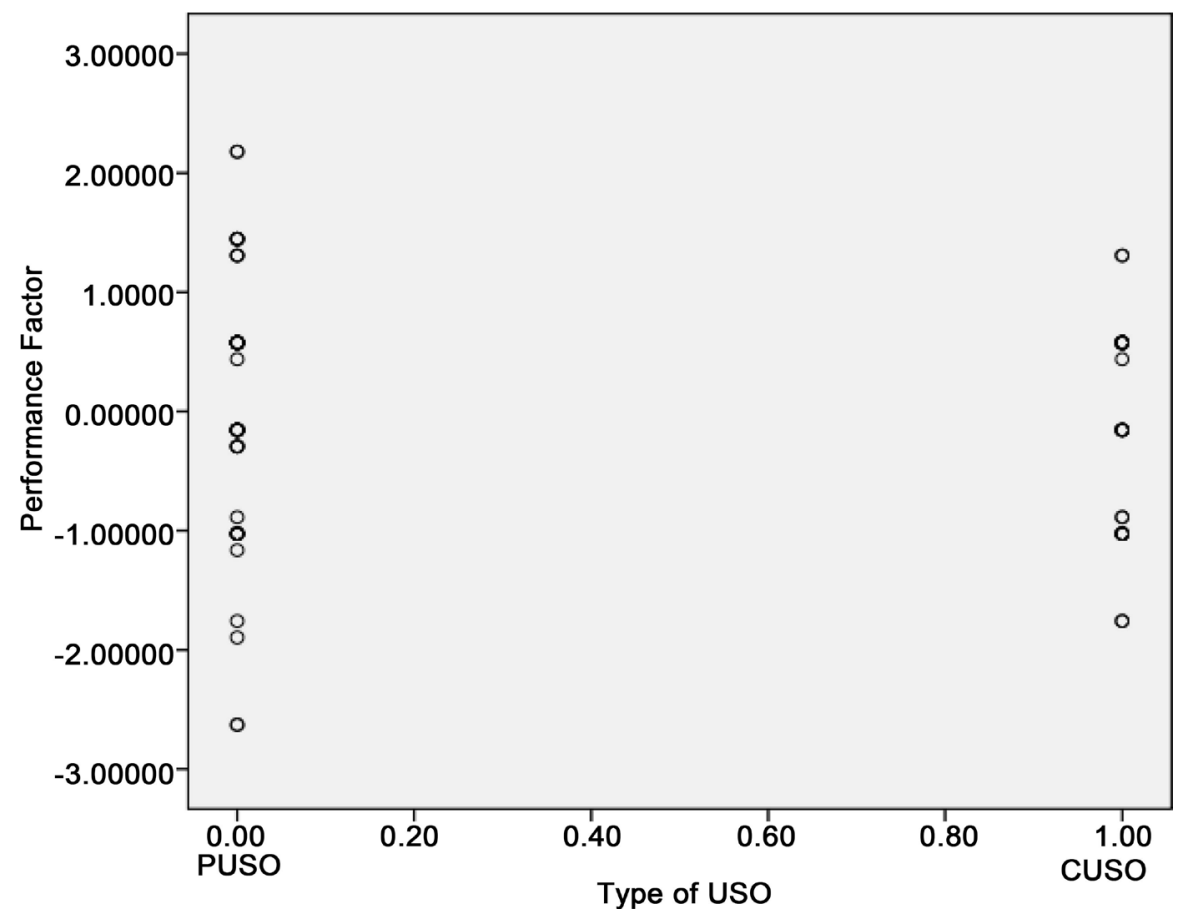

Figure 4. Type USO and PF.

tem of the 55 years of retirement age and this will drop the efficiency of the security system. The BMI also 2.2 units higher for the PUSOs compare to the CUSOs, this shows the appearance differences. In average number of leave taken by PUSO was 13.1 days higher for the PUSOs compare to the CUSOs and the number of leave taken is higher for the old employees. These all highlight the disadvantages having PUSOs in the university system compare to hiring CUSOs. 


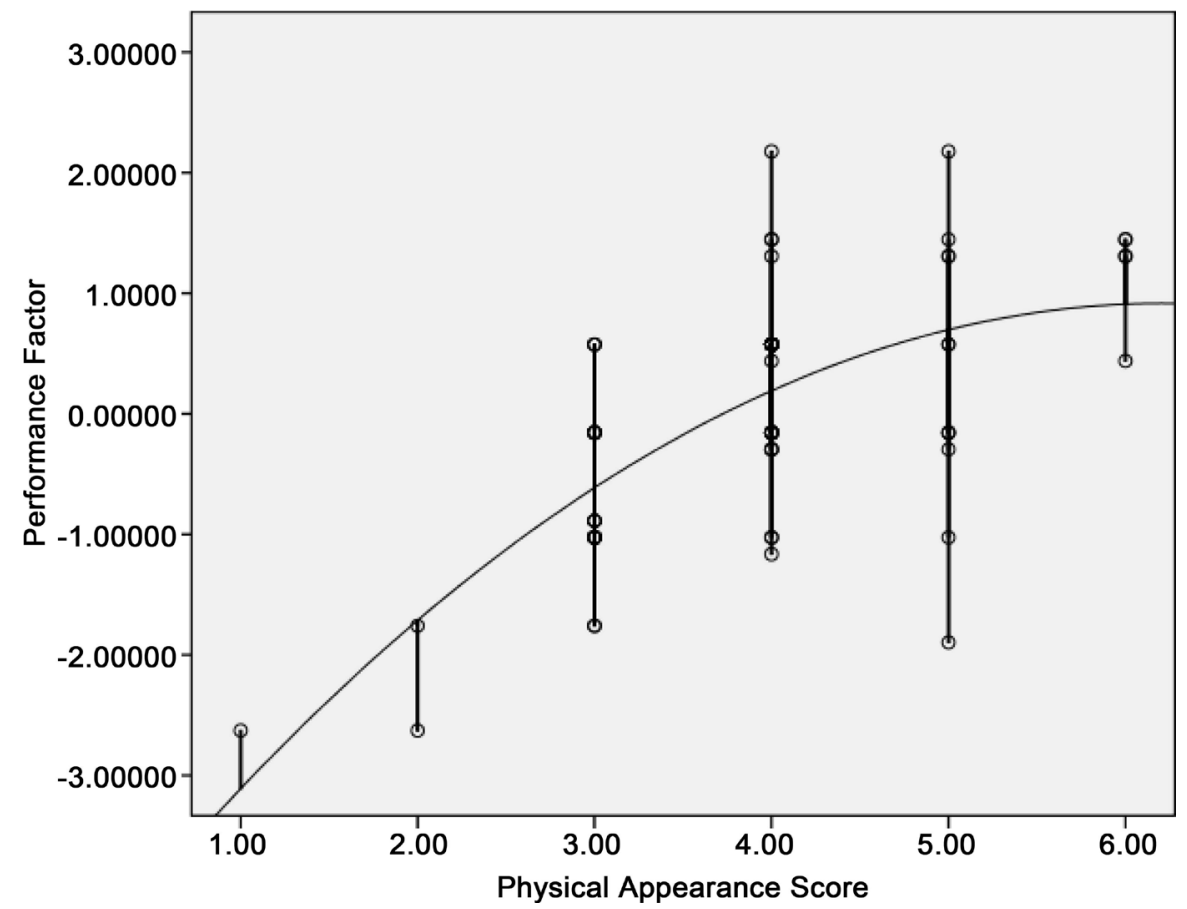

Figure 5. Relationship between Physical appearance and PF.

However the responsibility of the PUSOs is greater than the CSOs and it has to be compensated in deciding the system required for a university.

\section{References}

[1] Siciliano, R. (2010) Safety and Security on College Campuses. http://www.idtheftsecurity.com

[2] Brown, D. (2014) Importance of Security Officers and the Role They Play Today. Demand Media. Inc., Houston.

http://work.chron.com/importance-security-officers-role-play-today-15199.html

[3] Brown, J. (2003) How Do Your Alarms Communicate? York College, Pennsylvania. http://www.ycp.edu/about-us/offices-and-departments/campus-safety/york-collegeemergency-procedures/

[4] Badiwe. M., Osman, A. and Amadu. M.R. (2016) The State of Physical Security on Campuses of Tertiary Educational Institutions: The Role of the Security Guard. International Journal in Management and Social Science, 4, 418-429.

[5] Westlake, D. (2015) Characteristics of a Professional Security Officer. Demand Media Inc., Houston. http://www.igsprotection.com/security-guard-services-houston

[6] Smith, E., Watson, R. and Miller, B. (2012) Private Investigator and Security Guard Training Manual-Correction, Public Safety and Policing. Ministry of Justice and Attorney General, Canada. http://www.qp.gov.sk.ca/documents/forms/privateinvestigators/pisg-manual-12.pdf

[7] Iman, F. (2015) What Qualities Should a Security Officer Possess? Demand Media Inc., Houston. http://www.igsprotection.com/security-guard-services-houston

[8] Reeves, L. (2015) What Qualities Must You Have for a Security Job? Demand Media, Houston. http://www.igsprotection.com/security-guard-services-houston

[9] Andy, T. (2013) How to Implement Security Officer Physical Fitness Standards. http://www.securitymagazine.com/articles/84679-how-to01.09/2013 
[10] Liunoy, B.N. and Arie, L. (2006) Relationship between Changes in Neck Circumference and Cardiovascular Risk Factors. Experimental \& Clinical Cardiology, 11, PMC2274839.

Submit or recommend next manuscript to OALib Journal and we will provide best service for you:

- Publication frequency: Monthly

- 9 subject areas of science, technology and medicine

- Fair and rigorous peer-review system

- Fast publication process

- Article promotion in various social networking sites (LinkedIn, Facebook, Twitter, etc.)

- Maximum dissemination of your research work

Submit Your Paper Online: Click Here to Submit

Or Contact service@oalib.com 